\title{
INTERNATIONALIZATION OF POLISH Journals In THE Social ScIENCES AND Humanities: Transformative Role of The Research Evaluation System
}

\author{
EMANUEL KuLCZYCKI \\ Ewa A. Rozkosz \\ Aneta Drabek
}

Abstract. This article discusses the transformations of Polish journals caused by the Polish Journal Ranking evaluation system. We focused on the internationalization of journals in the social sciences and humanities $(N=801)$, with the goal of investigating how science policy has transformed editorial practices at Polish journals. We used a mixed-method approach involving both one-way analysis of variance, two-way mixed design analysis of variance, and semi-structured interviews. Our findings showed that science policy has transformed editorial practices, but that there is no actual internationalization in Polish social sciences and humanities journals. Rather, there is only the ostensible internationalization that manifests in "gaming" the journal evaluation system. We found that the editors of Polish journals do not discuss the challenges of internationalization, and implement only those internationalization practices that are explicitly required in the system regulations. We conclude with recommendations for how to motivate the internationalization of journals and stem the corruption of parameters measuring internationalization.

Keywords: Humanities, Internationalization, Poland, Polish Journal Ranking, Social Sciences

Résumé. Cet article porte sur les transformations des revues polonaises engendrées par le système d'évaluation des revues : Le Classement des Revues Polonaises. Nous nous focalisons sur l'internalisation des revues en sciences humaines et sociales $(N=801)$. L'objectif de notre étude est de déterminer comment la politique scientifique a transformé les pratiques éditoriales. Nous nous appuyons sur une approche méthodologique mixte qui réunit une analyse de la variance à un facteur, une analyse de la variance à deux facteurs dans le schéma mixte et des entretiens semi-directifs. Les résultats de notre analyse révèlent que 
la politique scientifique a transformé les pratiques éditoriales, mais qu'il n'existe pas d`internalisation réelle des sciences humaines et sociales. Il n〉existe qu>une prétendue internalisation qui se manifeste par un " détournement» du système d`évaluation des revues. Nous montrons qu'il n'y a pas de discussions relatives aux enjeux de l'internalisation chez les éditeurs qui se contentent de développer les aspects d'internalisation explicitement indiqués par la réglementation du système. Pour conclure, nous formulons quelques recommandations pour favoriser le développement de l'internalisation des revues et endiguer la corruption des paramètres.

Mots clés: Sciences humaines, Internalisation, Pologne, Classement des Revues Polonaises, Sciences sociales

\section{INTRODUCTION}

$S$ cience is as a practice that is international by its very nature (Gordin 2015). In contrast, the social sciences and humanities (SSH) are often described as closely connected to the surrounding culture, language, and society. Thus, the SSH are often perceived as more "national" than "international" (Kyvik 1988; Nederhof et al. 1989). Sivertsen (2016), however, shows that the publishing practices in the SSH were not originally "national". Scholars in the past used several international languages, among which Latin was the first. Sivertsen highlights that "nationalization" of the SSH is closely connected to the democratization of education and social life in the 20th century. In this way, knowledge legitimation in the SSH demands not only scientific peers but also society. The SSH function in the so-called "distorted universality" (Keim 2008) in which scholars have to reconcile the internationalization of scholarly communication with the localization of specific claims of scholars and society.

The term "internationalization" is used for describing transformation at three levels in research on higher education and science policy (Frølich 2006). At the macro level, there are transformations of the environments of science and higher education or institutions through various national and international policies. At the meso level, there are transformations that integrate an international dimension into the activities of institutions. At the micro level, the internationalization refers to international cooperation, co-authored publications, and mobility.

Science policy and higher education policy have addressed internationalization since the 1980s and 1990s (Aksnes et al. 2008; Reale et al. 2012). Initially, the term referred mainly to student mobility. However, internationalization is now perceived as a way of strengthening 
research excellence, increasing the attractiveness of the R\&D system, and responding to global problems. In Europe, the EU Framework Programmes have played a major role in encouraging international collaboration and contributed to an internationalization of funding agencies. From the 2000s, many policies have been developing both at European and national levels (e.g. the Lisbon strategy and the European Research Area). National policymakers seek ways to enhance the internationalization of research and higher education institutions in their countries. In constructing strategies to increase internationalization, different motivations and rationales might be involved, including the national configuration, the political will, and the current level of internationalization.

In our study, we have focused on the internationalization of journals in Poland. We have investigated how the internationalization parameters that quantify internationalization are constructed, and how, as a result, science policy has shaped and transformed the Polish journals in the SSH. The research evaluation system in Poland has been investigated only in several studies from which only a few - presenting the regulations and the legal side of this system - have been published in English (Kulczycki 2017; Kulczycki \& Rozkosz 2017). Thus, this study contributes to the knowledge advancement in the field of journal evaluation as it provides the very first results of research into the editorial practices transformations in Poland.

Internationalization of journals has become an important aim of science policy (Li \& Zhang 2003; Reza Davarpana \& Behrouzfar 2009) as well as a key criterion in various journal evaluation procedures (Brembs et al. 2013; Pontille \& Torny 2010; Wolters 2013). It is generally agreed that the concept of internationalization in scientific journal publishing has lacked a systematic definition (Zitt \& Bassecoulard 1998), and as a result, policy solutions are diverse for not only different fields of science, but also for different types of countries (English- and non-English-speaking). Internationalization of journals means more than just extending the national scene and adding a non-national orientation to the journal scope. For journals from non-English-speaking countries, internationalization also means publishing articles in English by local scientists, encouraging authors from foreign countries to publish in local journals, and reviewing articles by non-national scholars. Therefore, the challenges of journal internationalization have their own "logic" from the perspective of nonEnglish-speaking countries.

This study is structured as follows: first, we present background and context concerning science policy and research evaluation in Poland. Then, three data sets and analysis methods are described, followed by 
results, which focus on the parameters of journal internationalization and science policy regulations. In the final section, a conclusion is provided.

\section{BaCkground ANd CONTEXT}

Our framework consists of four pillars that allow us to interpret the results of a mixed-method explanatory study. First, we focus on the effects of science policy in Poland whose goals determine the system of the Polish Journal Rankings (i.e., second pillar) which is the main instrument of journal evaluation. In our study, we investigate the transformations of editorial practices and journals internationalization in the SSH. Then, by presenting the third pillar (i.e., the publication language in the social sciences and humanities), we argue that internationalization in terms of publication languages is a very complex issue for scholars from nonEnglish speaking countries. Finally, we present how internationalization of journals is measured in Poland and how indicators used in Poland can be compared to indicators used in other systems.

\section{Science Policy in Poland}

As one of the Central and Eastern European countries, Poland has undergone various transformations in academia in recent years (Albu \& Albu 2015; Kozak et al. 2014). After the breakdown of the Communist Regime, important systemic changes in university governance and funding modes were implemented. These changes have resulted in massive expansion of higher education institutions, while at the same time, Polish social sciences and humanities have lost significant amounts of international research visibility, and the so-called hard sciences have sustained their international research visibility (Kwiek 2014). In 2008, a policy statement entitled "Building on the Knowledge" was presented for the purpose of encouraging deep reforms of the science and higher education sectors (Ministerstwo Nauki i Szkolnictwa Wyższego 2008). These reforms started in 2010. Internationalization and enhancement of the quality of science have been the twofold aim of the reforms, and they have been expressed in various government acts.

One of the biggest systemic changes has been the building of a new research evaluation system that serves to distribute funding to all higher academic institutions (Kulczycki 2017). This system is a performancebased research funding system (PRFS) in which research is evaluated mostly through the number and quality of publications (Hicks 2012). The PRFSs used at the national level have various impacts and consequences. Butler (2003), when discussing the Australian case, argues that 
the funding formula based on the number of publications in a given database (the Science Citation Index in the case in question) and the rise of the culture of evaluation can change publication practices. Butler highlights that policy analysts should not take the simple bibliometric measures to improve the productivity in science. On the other hand, Schneider et al. (2014) show that publication goes up and (citation) impact remains stable in Norway. The different Australian and Norwegian experiences illustrate that various indicators and publication counts can influence productivity in different ways. Moreover, the shape of the databases built for the PRFS purposes can also determine our understanding of productivity in various groups of sciences. As the Flemish case shows, we need databases that cover the social sciences and humanities to investigate changes in the publication patterns in these areas (Engels et al. 2012).

All Polish scientific institutions submit for evaluation the research outputs of their employees every four years. The Polish PRFS is designed for all types of institutions and all groups of sciences; it is one system with the same criteria for evaluating both "hard sciences" (natural sciences, technology, engineering, and mathematics) and "soft sciences" (social sciences, humanities, and arts). In consequence, the most important parameters in the evaluation are articles published in international scientific journals, which are a crucial form of knowledge dissemination for many disciplines. However, books and edited volumes play a major role in various disciplines within the SSH, and their value in the Polish system is depreciated. For example, a scholar can obtain 50 points for publishing an article in the most "pointed" journal, but only 25 points for publishing a book with the most prestigious academic publishers (e.g. Cambridge University Press).

\section{Polish Journal Rankings}

The key element of the Polish PRFS is the Polish Journal Ranking, which allocates journals into three lists- $\mathrm{A}, \mathrm{B}$, and $\mathrm{C}-$ which translates the "quality" of articles published in these journals into "points" (Kulczycki et al. 2017a). The Polish ranking published since 1999 is one of the first national rankings. Other national rankings have been carried out, for instance, in Australia, Brazil, France, Netherlands, Norway, Serbia, and Spain. Those rankings are used - as the Polish one - mostly as components of the performance-based research funding systems.

In Poland, nearly 3,000 scientific journals are published, including more than 1,200 in the SSH. However, only a few journals in the SSH are indexed in international databases: 7 in the Social Sciences Citation Index, 6 in the Arts \& Humanities Citation Index, and 67 in SCOPUS. Ac- 
cording to Salager-Meyer (2015), the Polish situation is similar to those of China, Bangladesh, Slovenia, Iran and the Middle East in general, where only a small part of journals meets the minimum requirements for being covered by the major indexing services. That is why the majority of Polish journals in the SSH are not indexed in international databases, and are indexed only in the PJRs.

In our study, we define the social sciences as the social sciences field in the OECD Field Classification, and the humanities as the humanities field in the OECD classification (Organisation for Economic Co-operation and Development [OECD] 2007). However, disciplines included in these OECD fields are sometimes defined in a different way than in the Polish classification. For instance, two Polish disciplines, archeology and history, are a single discipline in the OECD classification. These definitions follow the regulations for journal evaluation in Poland, in which journals are assessed according to three major categories: social sciences (SS), humanities $(\mathrm{H})$, and the so-called hard sciences, which consist of engineering, natural sciences, and medical sciences (ENM).

The methodology of creating the PJRs has been described in an earlier study (Kulczycki \& Rozkosz 2017). The PJRs have been published for two decades. A new model of the PJRs was introduced in 2011, and on the basis of that model, three further PJRs were published in 2012, 2013, and 2015. A PJR is prepared by the Ministry of Science and Higher Education in Poland, which organizes journals into three lists-A, B, and C:

- The A list: journals indexed in the Journal Citation Reports (from 15 to 50 points)

- The $B$ list: Polish (until 2014, also foreign) journals without an impact factor (from 1 to 15 points)

- The C list: journals indexed in the European Reference Index for the Humanities (from 10 to 25 points).

For Polish scholars in the SSH, the most important list is the $B$ list, in which almost all of the Polish journals published in these fields are indexed. Hence, we have focused on this set of journals in our study.

In the $B$ list, the points have been assigned to the journals according to the fulfillment of the parameters in the multidimensional evaluation. Journals are evaluated according to their inclusion in one of the three categories: SS, H, and ENM. This category is assigned by the editor-inchief during the submission process. In each edition of PJR, the same parameters are used for all groups. Thus, if some journals are indexed in all PJRs prepared pursuant to the new model presented in 2011, it is pos- 
sible to compare transformations and the evaluation results of selected journals.

\section{Publication Language in the Social Sciences and Humanities}

The choice of language for academic publications is a very complex issue for Polish scholars (Duszak \& Lewkowicz 2008). It depends on the age of researchers (Russian was a compulsory language at school prior to 1989), a previous exposure to English, and the fields of studies. Writing about the Hong Kong context, Hyland (2016) shows that the dominance of English in the Academia has raised the question of the possible 'linguistic injustice' against authors' mother tongues. In Poland, many scholars perceive publishing in English as such a type of injustice because they publish mostly in Polish. For the 2009-2014 period, only a small percentage of works in the social sciences and humanities was written in English (11.8\%) and publications in Polish (82.7\%) constituted the majority of all academic work (Kulczycki et al. 2017b). On the other hand, as Sivertsen (2016) shows, publishing in the native language and in an international one is the regular practice of the majority of Norwegian researchers in the SSH. Nonetheless, authors from non-Englishspeaking countries must seek acceptance in an English-only research world. It has become an obligation even in the SSH. Bocanegra-Valle (2013) argues that the general trend in Europe might be illustrated by the Spanish situation: there is no legislation protecting the national language. Thus, English is actually the very language of research and is highly valued by researchers as the best way to be acknowledged and recognized. This description fits actually the Polish situation. In Poland, scholars are free to publish in Polish, but must publish in English if they want to obtain research funding and a habilitation (the highest scientific degree). However, it means that not only do scholars need to publish in English, but also that Polish journals must transform their scope and editorial practices from a local to an international orientation.

\section{Indicators and Parameters of Journal Internationalization}

There is a wealth of literature on the internationalization of journals. The most often-used indicators are the following: publication language (Buela-Casal et al. 2006; Rey-Rocha \& Martin-Sempere 2004), international audience (Buela-Casal et al. 2006), reviewer(s) affiliation (Pajić \& Jevremov 2014), and author(s) affiliation (Wormell 1998). Sivertsen (2016) shows that using the international cooperation indicators is limited in the SSH because of the domination of single-authored articles in those fields of study. Moreover, other indicators are used, such as edi- 
torial board member(s) affiliation (Rey-Rocha \& Martin-Sempere 2004) and indexing in the bibliographic databases - their international nature is not crucial because the indexing itself (which can improve the visibility of the journals) is far more important than the types of databases. (Buela-Casal et al. 2006; Rey-Rocha \& Martin-Sempere 2004). By using the indicator "indexing in the bibliographic databases", one can assess if journals provide access to their publications for the broader international audience. The internationalization indicators are closely related to the prestige indicators, such as citations (Gutiérrez \& López-Nieva 2001) and to peer-reviews performed by international peers (Yue \& Wilson 2004).

In science policy in Poland, four internationalization parameters are used within the journal evaluation system. In the official documents, they are sometimes called "indicators", but usually "parameters". However, there does not appear to be any pattern to when the terms are used. Hence, in the present study we have decided to use the term "parameters". In general, such parameters can be classified into five dimensions of journal evaluation: (1) content, (2) output, (3) perception and usage, (4) citation, and (5) journal management (see Haustein 2012). In the Polish system, internationalization is measured only within two dimensions. The first one is the dimension of output, which involves parameters related to the publication language and the authors' affiliations. The other dimension is journal management, which involves parameters related to the reviewers' affiliations and the editorial board members' affiliations. Thus, transformations of Polish journals are determined from both sides: ministerial regulations that require the internationalization, and scholars that need international publications.

Polish journals face similar challenges as do journals in other Central and Eastern European Countries and journals from other periphery countries Salager-Meyer (2015). According to Šipka (2013), Serbian journals are also evaluated, and one of the main goals of evaluation is to stimulate the process of internationalization of national research publishing. ŽicFuchs (2014) shows that Croatian medical journals are more frequently published in English which results in decreasing the number of journals that publish (papers of poorer quality) in Croatian. Spanish journals are also assessed according to their international impact and international visibility (Giménez-Toledo et al. 2007). Such a shift to international audience has caused a mass migration of the best research articles to foreign journals in Spain. Nonetheless, the Spanish case shows that science policy can be efficient in stimulating the productivity and internationalization of research (Jiménez-Contreras et al. 2003). 
Not every Polish scholar is able to publish in prestigious international journals. Hence, they need some journals that are "international" in a national context, meaning journals that allow them to publish in English and to be reviewed by international referees. For those scholars, it might be the first step toward publishing in journals that are more prestigious and likely to be read by the scholarly community of a given discipline. It is particularly important for early stage researchers who need to practice their academic writing. Salager-Meyer (2008) has highlighted that one of the key problems of local journals is that their readership is very small and hardly ever transcends national boundaries. This means that such journals, as a rule, are read only by those who publish in them. However, many national journals have a greater readership than international periodicals within each country.

\section{Methodology}

In our study, we have examined the internationalization of journals at the micro level in terms of the above mentioned three levels of internationalization. This approach has highlighted processes and editorial practices at play. We have conducted a mixed-method sequential explanatory study (see Creswell 2014), consisting of statistical analysis and semistructured interviews, to investigate the internationalization of Polish journals and to determine how the government regulations have affected the editorial practices in the SSH. In our analysis, we have focused on the Polish journals that are indexed in the Polish Journals Rankings (PJRs). The study consists of two phases. In the first phase, we have collected and analyzed the quantitative data on the internationalization of 1,356 journals from all groups of sciences, of which 801 were from the SSH. In the other phase, we have interviewed editors of $15 \mathrm{SSH}$ journals which were selected from the journals analyzed in the first phase. The second phase has allowed us to understand in-depth the results of quantitative analysis. The results of each phase are presented separately and, finally, they are integrated and discussed in the Discussion section.

For the purpose of this study, we collected data giving a complete representation of the Polish journals in the SSH.

The main aim of our analysis was to determine how science policy has driven the internationalization of journals in the SSH in Poland. Three data sets (I, II, III) contain journals indexed in the B lists of all three PJRs. We have used each of sets for a specific aim: 
I. For the analysis of the internationalization of journals in the $\mathrm{SSH}$, we used data from the PJR published in 2012, 2013, and 2015. The unit of analysis is a journal. We analyzed journals that were indexed in each of the three editions of the PJRs in 2012, 2013, and 2015. These journals were classified into one of three groups: SS, H, or ENM. By implementing such criteria, we selected 422 journals in the SS, 379 journals in the $\mathrm{H}$, and 555 journals in the ENM. Finally, we analyzed 801 journals from the SSH. Data were received from the National Information Processing Institute in Poland, which was the technical operator of the multidimensional evaluation.

II. For the more specific analysis of the internationalization of journals, we used data that were defined and collected in the same way as in data set I. We aggregated journals at the level of disciplines according to the Polish classification, and chose journals from four representative disciplines. Our choice was determined by the fields of expertise of the authors of the present study. We assigned a journal to a discipline in two steps. In the first step, we selected all journals that were assigned to a given discipline in the PJR in 2015 (a journal could be assigned to one or two disciplines). In the other step, we accepted or rejected a journal for the analysis. Our decision was informed by: (1) information and discipline classifications retrieved from the ARIANTA (the largest continuously updated database of Polish journals); (2) results of the expert-based assessment within the multidimensional journal evaluation (a journal could be acknowledged as "outstanding" or "significant" for a given discipline, such as philosophy, by the experts from the Committee of Philosophical Sciences of the Polish Academy of Sciences); and (3) information retrieved from the journals' websites. Data set II included 82 journals from the social sciences (consisting of 41 journals from sociology and 41 journals from educational sciences) and 87 journals from the humanities (consisting of 42 journals from philosophy and 45 journals from history). We chose these disciplines because they are representative for the $\mathrm{SSH}$, and this choice allowed us to analyze the disjoint sets with a similar number of journals within.

III. For the qualitative analysis of a transformative role of the research evaluation system, we conducted 15 semi-structured interviews with editors-in-chiefs or managing editors of Polish journals from the SSH. We focused on journals that had been published for at least 5 years. Table 1 shows the characteristic 
of the journals included in this qualitative study. To secure anonymity of the journals, we show the range of years reflecting the age of journals and the range of points reflecting how these journals were rated in the three Polish Journals Rankings (the minimum and maximum values).

Table 1. Description of journals from data set III.

\begin{tabular}{|c||c|l||c||c|}
\hline \multicolumn{1}{|l|}{ Journal ID } & Group of Science & Discipline & Age (in 2015) & Points \\
\hline 1 & Humanities & Culture studies & $<11,25>$ & $5-8$ \\
\hline 2 & Humanities & Culture studies & $<26,50>$ & $5-12$ \\
\hline 3 & Social Sciences & Psychology & $<11,25>$ & $5-11$ \\
\hline 4 & Humanities & Philosophy & $<26,50>$ & $5-12$ \\
\hline 5 & Social Sciences & Sociology & $<5,10>$ & $3-10$ \\
\hline 6 & Social Sciences & Education studies & $<5,10>$ & $4-11$ \\
\hline \hline 7 & Humanities & Art sciences & $<11,25>$ & $5-7$ \\
\hline \hline 8 & Humanities & History & $<11,25>$ & $4-12$ \\
\hline 9 & Humanities & Philosophy & $<5,10>$ & $4-10$ \\
\hline 10 & Social Sciences & Education studies & $<5,10>$ & $3-8$ \\
\hline 11 & Social Sciences & Media studies & $<11,25>$ & $8-10$ \\
\hline 12 & Humanities & Literature & $<5,10>$ & $1-5$ \\
\hline 13 & Humanities & Book studies & $<5,10>$ & $4-6$ \\
\hline 14 & Humanities & Information Science & $<50,100>$ & $3-8$ \\
\hline 15 & Humanities & Ethnography & $<50,100>$ & $1-10$ \\
\hline & & & & \\
\hline
\end{tabular}

The aim of interviews was a deep understanding of the science policy in the area of journal evaluation and the transformations of editorial practices resulting from this policy. We asked the interviewees about their experiences with publicizing their journals and adjusting their practices according to the research evaluation system (see themes and sample questions in the Appendix). Interviews were conducted in Polish and the average interview length was approximately 45 minutes. We used non-random purposive sampling, which means that the selection of participants was based on a specific criterion: journals were selected from journals included in data set I (indexed in the B list of the three PJRs). 
We analyzed three data sets according to the following specific methods:

I. For the analysis of data set I, we selected four parameters from all parameters used in the multidimensional journal evaluation process in Poland: the percentage of (1) authors from foreign countries, (2) reviewers from foreign countries (IntRev), (3) articles published in the so-called congress languages, i.e. English, German, French, Spanish, Russian, and Italian (IntLang), and (4) members of the editorial advisory board from foreign countries (IntEdit). Moreover, we used for analysis the values of internationalization parameters in the PJRs published in 2012, 2013, and 2015 (we refer to a year in which a PJR was published as a measure time). We analyzed this data set in two steps. Firstly, we performed one-way analysis of variance (ANOVA) with repeated measures and tested how the value of internationalization parameters changed over time in three groups of sciences (SS, H, and ENM) separately. A measure time $(2012,2013,2015)$ was the within-subject factor. We conducted the post hoc tests using the Bonferroni correction for revealing the differences between the values of parameters in individual measure times. Secondly, we performed one-way ANOVA and tested the differences between the mean values of each internationalization parameter in SS, $\mathrm{H}$, and ENM for each measure time. A group of science (SS, H, and ENM) was the between-subjects factor. The Scheffé post hoc test was then employed to determine the nature of the differences between the groups of sciences. We have presented the most significant results. Following Cohen (1988), we used $\eta^{2}$ as a measure of the effect size and used the following ranges for interpretation: small effect size: $<.06$, medium effect size: $.06-.14$, and large effect size: $>.14$.

II. For the analysis of data set II, we used the same internationalization parameters (IntAut, IntRev, IntLang, IntEdit) but our investigations were conducted on a different level of data aggregation. Instead of analyzing whole groups of the social sciences and the humanities, only four selected disciplines were analyzed. We compared the values of each internationalization parameter between the journals from four disciplines: sociology, education studies, philosophy, and history. Moreover, we compared values of each parameter in three measure times: 2012, 2013, and 2015. We investigated if there were any differences between the values for disciplines according to the mea- 
sures times. We performed a two-way mixed design ANOVA for four disciplines $\times$ three measure times. A discipline was the between-subjects factor and a measure time was the within-subject factor. An internationalization parameter was the dependent variable. Each parameter (IntAut, IntRev, IntLang, IntEdit) was calculated separately. The Bonferroni post hoc test was then employed to determine the direction of the differences between the parameters values of the journals classified in the various disciplines. We have presented the most significant results.

III. All interviews were audiotaped, independently transcribed, and entered into MAXQDA. Transcripts were coded and categories were developed, refined and validated by the authors of the present paper. The initial coding scheme was determined by the results of the quantitative analysis (for data sets I and II) and multiple readings of the regulations on multidimensional journal evaluation in Poland. In terms of analysis, we coded the data with a focus on the topics of science policy (e.g. regulations for journal evaluation) and the orientation of editorial practices toward a local or international audience. The relevant parts of transcribed interviews were highlighted and selected for further analysis. Excerpts from interviews with which we have illustrated results have been translated from Polish into English.

\section{Results}

\section{Part I.}

\section{Part 1.1: Ostensible Internationalization}

Our analysis conducted separately for each internationalization parameter shows that the values of IntRev, IntLang, and IntEdit have changed in all groups of sciences. The value of IntAut has significantly changed in two groups $(\mathrm{SS}, \mathrm{H})$ but not in the ENM. Table 2 presents detailed results that show the main effect of measure time, with a statistical significance level of $p<.05$. According to the value of $\eta^{2}$, there are differences between the effect size for individual parameters. The effect size was calculated separately for each group of science. In Table 2, however, we have presented the consolidated results. For three parameters, IntAut, IntRev, and IntLang, the effect size is small or medium in those groups of sciences in which the differences between the values of parameters were significant. Only for IntEdit is there a large size effect for all groups of sciences. 


\section{Table 2}

Means, standard deviations, and one-way analyses of variance (with a Greenhouse-Geisser correction) with repeated measures for the effect of measure time on dependent variables: Internationalization of authors, Internationalization of reviewers, Internationalization of language, and Internationalization of editorial board, in three groups of sciences: social sciences (SS), humanities (H), and engineering, natural sciences, and medical sciences (ENM) $M$ - mean; $S D$ - standard deviation; $F-\mathrm{F}$ ratios; $\eta^{2}-$ effect size; $d f-$ degrees of freedom.

\begin{tabular}{|c|c|c|c|c|c|c|c|c|}
\hline \multirow[t]{2}{*}{ Variable and source } & \multicolumn{2}{|c|}{$\begin{array}{l}\text { Measure in } \\
2012(1)\end{array}$} & \multicolumn{2}{|c|}{$\begin{array}{l}\text { Measure in } 2013 \\
\text { (2) }\end{array}$} & \multicolumn{2}{|c|}{$\begin{array}{l}\text { Measure in } \\
2015(3)\end{array}$} & \multirow[t]{2}{*}{$F$} & \multirow[t]{2}{*}{$\eta^{2}$} \\
\hline & $M$ & $S D$ & $M$ & $S D$ & $M$ & $S D$ & & \\
\hline \multicolumn{9}{|c|}{ Internationalization of authors } \\
\hline $\mathrm{SS}^{\mathrm{b}}$ & 10.56 & 17.14 & 11.55 & 17.94 & 12.81 & 17.68 & $8.698^{* *}$ & .02 \\
\hline $\mathrm{H}^{\mathrm{a}}$ & 15.39 & 19.73 & 16.87 & 20.76 & 16.85 & 19.72 & $3.203 *$ & .01 \\
\hline $\mathrm{ENM}^{\mathrm{c}}$ & 16.82 & 24.08 & 17.4 & 24.35 & 16.69 & 22.93 & .6 & .00 \\
\hline \multicolumn{9}{|c|}{ Internationalization of reviewers } \\
\hline $\mathrm{SS}^{\mathrm{b}}$ & 7.65 & 18.39 & 11.77 & 19.71 & 16.86 & 22.72 & $61.88^{* *}$ & .128 \\
\hline $\mathrm{H}^{\mathrm{a}}$ & 11.57 & 21.24 & 15.75 & 22.94 & 17.91 & 23.69 & $23.89 * *$ & .06 \\
\hline $\mathrm{SEM}^{\mathrm{c}}$ & 15.06 & 24.72 & 17.67 & 25.42 & 19.71 & 25.93 & $14.24 * *$ & .02 \\
\hline \multicolumn{9}{|c|}{ Internationalization of language } \\
\hline $\mathrm{SS}^{\mathrm{b}}$ & 19.56 & 33.17 & 21.27 & 33.62 & 27.05 & 34.58 & $46.7^{* *}$ & .1 \\
\hline $\mathrm{H}^{\mathrm{a}}$ & 21.33 & 35.11 & 23.68 & 35.06 & 25.62 & 34.05 & $19.34 * *$ & .05 \\
\hline $\mathrm{ENM}^{\mathrm{c}}$ & 40.37 & 44.87 & 41.64 & 44.51 & 46.15 & 44.84 & $26.19^{* *}$ & .04 \\
\hline \multicolumn{9}{|c|}{ Internationalization of editorial board } \\
\hline $\mathrm{SS}^{\mathrm{b}}$ & 28.02 & 27.39 & 35.12 & 26.67 & 41.82 & 24.32 & $124.1 * *$ & .23 \\
\hline $\mathrm{H}^{\mathrm{a}}$ & 27.03 & 25.2 & 32.28 & 24.59 & 40.51 & 23.26 & $115.74 * *$ & .23 \\
\hline $\mathrm{ENM}^{\mathrm{c}}$ & 30.14 & 26.54 & 34.72 & 27.3 & 40.90 & 26.49 & $105.56^{* *}$ & .16 \\
\hline
\end{tabular}

$M$ - mean; $S D$ - standard deviation; $F-\mathrm{F}$ ratios; $\eta^{2}$ - effect size; $d f$ - degrees of freedom.

${ }^{\mathrm{a}} d f=378,{ }^{\mathrm{b}} d f=421,{ }^{\mathrm{c}} d f=554$.

${ }^{*} p<.05 . * * p .001$ 
To determine which parameters increased in all groups of sciences, we conducted a post hoc analysis with the Bonferroni correction for multiple comparisons. Our analysis revealed a significant increase in two parameters (IntRev and IntEdit) in two measure times (2013 and 2015), at a statistical significance level of $p<.001$ in all groups of sciences.

In summary, in all groups of sciences, the primary effect of science policy in terms of the internationalization parameters has been a change in the composition of editorial advisory boards, as measured by the IntEdit parameter. Furthermore, journal editors from both the soft and the hard sciences increased the percentage of reviewers from foreign countries, as measured by the IntRev. Two other parameters, IntAut and IntLang, did not change in Figure 1. The mean value of the internationalization parameters in three groups of sciences: social sciences (SS), humanities $(\mathrm{H})$, and engineering, natural sciences, and medical sciences (ENM).

\section{Part I.2: Local Orientation of the Social Sciences and Humanities}

Our analysis conducted separately for each internationalization parameter found that the values of IntAut and IntLang were significantly different between groups of sciences at all measure times. Moreover, IntRev was significantly different between group of sciences in 2012 and 2013. This means that there is a main effect of the group of sciences, and parameter values were significantly different between at least two of the analyzed groups. We did not observe any significant differences for the IntEdit parameter at any measure times, nor a significant difference for the IntRev in 2015. The effect of the group of sciences was the highest (medium effect size) for the IntLang: $F(2,1353)=43.493, \mathrm{p}<.001, \eta^{2}=$ $.06 ; \mathrm{F}(2,1353)=40.615, \mathrm{p}<.001, \eta^{2}=.06$; and $\mathrm{F}(2,1353)=42.343, \mathrm{p}$ $<.001, \eta^{2}=.06$, for 2012, 2013, and 2015, respectively. Scheffé post hoc tests showed that the values of IntLang differed at the $p<.001$ level between the SS and the ENM, and between the H and the ENM. In the soft sciences (SS and $\mathrm{H}$ ), the values of IntLang were lower in all measures times than in the hard sciences (ENM). Figure 1 illustrates this relationship, and demonstrates the distinct relevance of language in soft and hard sciences. 
Figure 1. The mean value of the internationalization parameters in three groups of sciences: social sciences (SS), humanities (H), and engineering, natural sciences, and medical sciences (ENM).

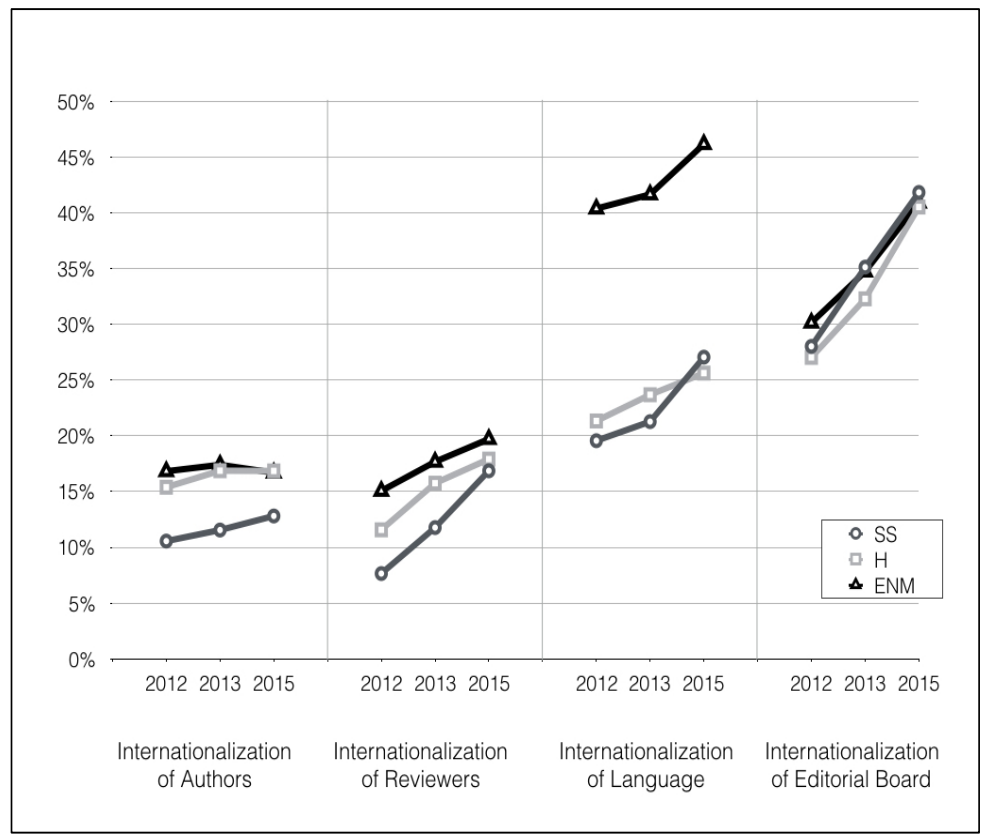

\section{Part II: Similarities and Differences of Internationalization Within Disciplines}

Further analysis conducted separately for the internationalization parameters showed that there was a main effect of time or a main effect of discipline for journals from four selected disciplines: sociology, education studies, philosophy, and history. Moreover, analysis revealed no interaction between the effect of time and the effect of discipline.

We observed no main effect for the IntAut parameter, but did observe a main effect of time for three other parameters (IntRev, IntLang, IntEdit) on the levels of, respectively: $F(2,330)=18.17, p<.001, \eta^{2}<$ $.01 ; F(2,330)=21.85, p<.001, \eta^{2}=.12 ;$ and $F(2,330)=48.82 ; p<$ $.001 ; \eta^{2}=.228$.

According to the value of $\eta^{2}$, there were differences between the effect size for individual parameters. The size of the time effect was small for the IntRev, medium for the IntLang, and large for IntEdit. 
No main effect of discipline for the IntAut, the IntRev, or the IntEdit was found. For the IntLang, we observed a main effect of discipline at the level of $F(3,165)=3.674, p=.013, \eta^{2}=.063$. The value of $\eta^{2}$ shows that the effect size is medium and different between disciplines. As Figure 2 illustrates, regardless of the time of measurement, journals from sociology have higher values of the IntLang than journals from educational sciences, philosophy, and history.

In summary, similar to the results of Part I, we have found a high increase in the percentage of editorial advisory board members, but no significant increase in the percentage of authors from foreign countries for all measures times. We interpret these results as indicative of ostensible internationalization. We have also shown that there are differences between the language of publication in various disciplines. These differences might be explained in terms of differences between the publication practices in the various fields of study.

Figure 2. The mean value of the Internationalization of Language in four disciplines: sociology, educational sciences, philosophy, and history. The Internationalization of Language was measured in 2012, 2013, and 2015.

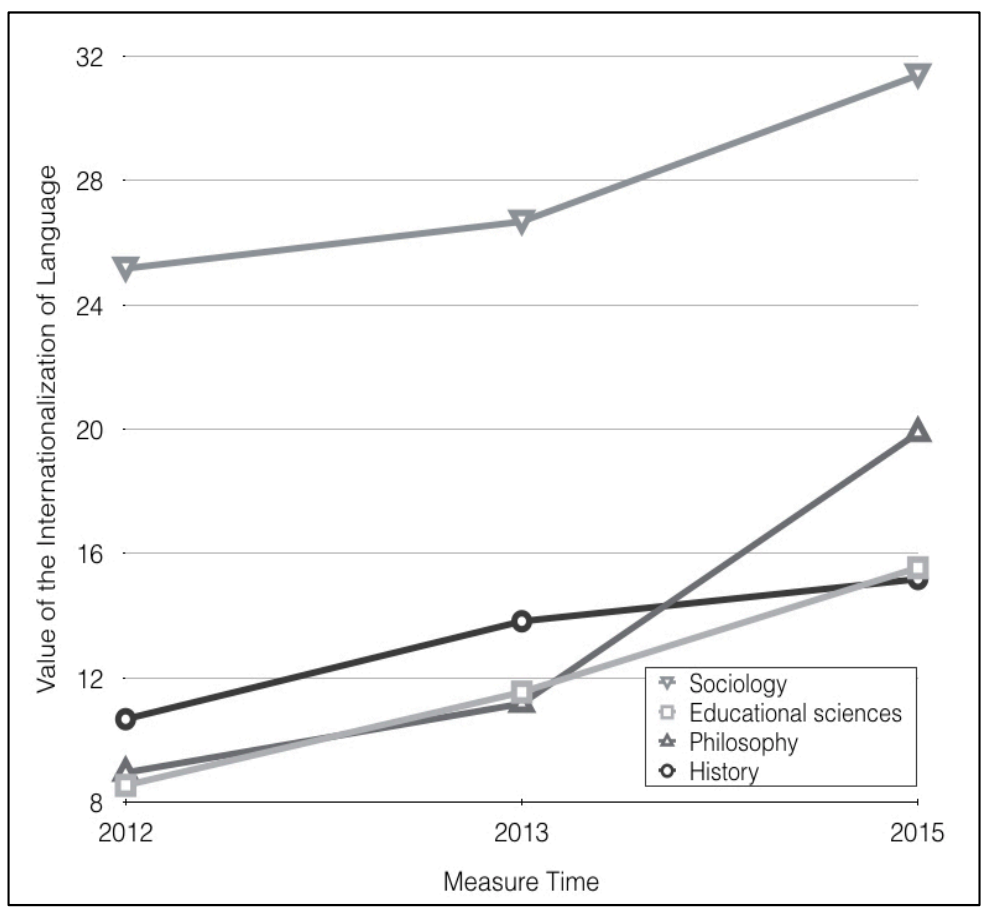




\section{Part III: Semi-Structured Interviews}

Our interviews have revealed important themes about the understanding of science policy and the attitudes of editors to this policy. The understanding of science policy was intertwined with the editors' attitudes and, in consequence, with an implementation or a rejection of the recommendations that result from this policy. Thus, some shared elements are described below.

\section{Understanding of Science Policy on the Evaluation of Journals}

Many interviewees made comments that highlighted the importance of the PJRs for the editors' work. Two editors explicitly stated that the number of points assigned to journals reflects the scientific quality of these journals. Points are important for authors, editors, and decision makers in various higher education institutions. In Poland, a majority of journals are financed from public funds. Hence, as interviewees expressed several times, deans and rectors of universities, who actually distribute money, take into account the number of points in their decisions. For instance, Interviewee 14 described a relation between funding and points as follows:

"Our university - I mean - the rector has upheld the funding [of a journal] if a journal has obtained the ministerial points."

One of the interviewees said that journals are supported by the university presses, especially (and sometimes only) in the process of obtaining more points. The interviewed editors of journals published for at least 5 but no more than 10 years stated that editors of journals that have been published for 25 or more years very often do not care about fulfilling the evaluation parameters. These results, however, from outdated editorial practices and forms of non-digital distribution, and not from declining the evaluation process itself.

On the whole, editors were aware that there is some system of national journal evaluation in Poland. They knew general and sometimes specific regulations on, e.g. indexing in the databases. During the interviews, they often used names of the most important databases from the science policy perspective, i.e. CEEOL (Central and Eastern European Online Library), CEJSH (Central European Journal of Social Sciences and Humanities), and ERIH (European Reference Index for the Humanities). Editors highlighted that their journal had just been indexed or that they were going to submit their journal for indexing. Some of those 
editors claimed that indexing of journals in the databases was a duty of the university presses or publishing houses, not the editorial staff:

"It means that indexing in all databases and, in general, our journal life on the Internet, is a matter of the publishing house. We almost do not cope with such matters [...]." (Interviewee 3 )

However, only one editor knew exactly what parameters and criteria are evaluated within the PJRs. Other editors understood, for instance, that publishing articles in English might raise a number of the points, but they could not provide any details. Moreover, editors mentioned some regulations that they believed to be official regulations of the PJRs. For instance, one editor claimed that their journal could not publish any advertisements because that could lower the number of points. In fact, such regulations have never been implemented in the Polish system.

\section{Attitudes to Science Policy: National and International Orientation}

One of the most significant aspects of the qualitative approach that we employed in this study is that it provides a good opportunity to uncover the editors' attitudes to science policy in the area of journal evaluation.

In almost all interviews, editors highlighted that journal evaluations and the PJRs regulations influence or even determine the work of the editorial staff and university presses. Many editors gave accounts of their editorial practices that highlighted applications of the science policy regulations. One editor argued that the PJR is "a stimulant of good editorial practices". The same editor highlighted that they founded a journal website only because it was a way to obtain more points.

In the opinion of many interviewees, science policy forces various actions on the editorial staff. Adjusting editorial practices to the regulations is initially perceived as an artificial action. Eventually, these artificial actions generally transform into various legitimate practices. However, some editors claimed that various editorial practices are tailored only for fulfilling the evaluation parameters (such as updating information about reviewers on the websites of journals) or-even stronger-some practices were referred to as "fake" ones. The most frequently-emphasized practice that serves to manipulate a parameter is adding some editors or reviewers from a foreign country, who actually do nothing in a given journal, or removing some Polish editors or reviewers:

"Members of the editorial advisory board from foreign countries, let us agree, are actually a square peg in a round hole [they are not suited to their position]." (Interviewee 6) 
"We update a list of reviewers when some changes have appeared, for instance, a change in the regulations of assigning points." (Interviewee 7)

The only purpose of those actions was gaming the related parameter, i.e. manipulating the values of IntEdit and IntRev. Gaming might be understood as bypassing an official regulation, e.g. a journal meets only a formal part of the regulation (by adding a member to the editorial board from a foreign country) but in reality no editorial improvement takes place (the new member does actually nothing) and the manipulation of the parameters was intended from the very beginning. A remark concerning members of the editorial advisory board from foreign countries might be confirmed by an experience of one of the authors of the present paper who maintains ARIANTA, the abovementioned database of Polish journals. Gaming the IntEdit and IntRev parameter has been ongoing since these parameters were introduced in the PJRs regulations.

Editors highlighted difficulties caused by a lack of money and constantly changing regulations in the PJRs. This appeared to be a major area of discussion at the editorial meetings. In the opinion of interviewed editors, the internationalization of journals is retarded mostly by a lack of funding, e.g. for translating articles written by non-Polish scholars (from a foreign language to Polish). Such articles, regardless of whether they were previously published, are very often labeled as original papers in Polish journals, and in this way they increase IntAut values. Moreover, there is no funding for translating journal websites or abstracts, or for proofreading papers written in a foreign language by Polish scholars.

"We are ready to add an English version of our journal website but- $-\mathrm{I}$ will say it in this way - the anglicists value themselves." (Interviewee 9)

"A good and known author guarantees a good paper that we could translate and promote the whole issue in this way." (Interviewee 15)

Internationalization is mostly considered to be a way to obtain more points, not as an aim itself or a way for promoting a journal and its content. Moreover, when we asked editors how and where they promoted their journals, most of the interviewees declared that they promoted journals only locally, i.e. at their universities and cities by organizing events when a new issue was published. Promoting new issues in non-local, Polish academic cities was stated as a goal by all except two of the interviewed editors.

One editor presented important reasons that show why editors might not be interested in internationalization. These reasons are habits and expectations of the current readers and subscribers, especially academic 
libraries. If journals start publishing all or just a few texts in English, then some libraries could stop subscribing to them, because readers want what they know.

In a majority of journals, changes in editorial practices are perceived in the context of evaluation criteria, rather than as good practices followed by other prestigious and international journals. However, two interviewees highlighted that the most prestigious journals in their field are a reference point for transforming current practices. Editors of those two journals perceive an evaluation of journals as a mechanism that can inform and guide journal development.

\section{Discussion}

This paper has argued that in general, science policy has transformed editorial practices in Polish journals through the establishment of internationalization parameters. Nonetheless, the internationalization that the parameters were intended to bring about has not become a reality, and there is no actual internationalization of journals in the SSH. In other words, one could say that the implementation of the bibliometric indicator and the resulting changes in the scientific productivity in Poland resemble the Australian experiences (Butler 2003) rather than the Norwegian ones (Schneider et al. 2014). All these three cases (Australian, Norwegian, Polish) are different but they lead to the similar conclusion: using a simple parameter to regulate and transform the publishing practices has always various unexpected and unintended consequences. Implementing a wrong parameter can not only bring no desirable results but - what is more important - can worsen the academic situation in a given country.

The internationalization of Polish journals is only ostensible and manifests itself in two changes within the editorial practices in Polish $\mathrm{SSH}$ journals. The first change is a considerable increase in the percentage of editorial advisory board members and reviewers from other countries. The other change is a minor increase in the percentage of authors from other countries (shown by the results in the Parts I.2 and the Part II). The ostensible character of internationalization is revealed by various practices: articles written in congress languages and published in Polish journals are distributed only to the local audience (the Part III), the values of internationalization parameters are adjusted (e.g. by adding or removing editorial advisory board members) solely for the purpose of obtaining more points (the Part III). In the interviews, editors characterized such editorial practices as gaming. This gaming allows us to under- 
stand why the values of the IntEdit and IntRev parameters are increasing more than the values of the IntAut and IntLang. Editors can manipulate the IntEdit and IntRev parameters much more easily, because these parameters are not directly controlled by the audience or evaluators. On the other hand, the IntAut and the IntLang are more transparent, e.g. because everyone can calculate a percentage of the papers published in congress languages. Interesting that the values of the IntAuth remain almost the same in all groups of sciences (see the Part I). That can be explained, for instance, by the attractively of Polish journals for foreign authors. As Salager-Meyer (2015) argues, the author pool of such periphery scholarly journals is limited. It is noteworthy to add that the value of the IntAut and the IntLang for Polish journals is almost equal to other journals in this part of Europe, e.g. for Serbian journals (Šipka 2013).

The ostensible internationalization of Polish journals shows that the so-called Campbell's Law applies in this case. Campbell wrote: "The more any quantitative social indicator is used for social decision-making, the more subject it will be to corruption pressures and the more apt it will be to distort and corrupt the social processes it is intended to monitor" (Campbell 1979: 85). The internationalization parameters were intended to regulate and motivate the process of internationalization. However, they have become a target and a way of achieving goals other than those originally intended, i.e. obtaining the evaluation points. As Butler (2003) illustrated, increasing the productivity by using a simple bibliometric indicator can also cause a significant decline in the citation impact: when we measure one practice, we can change - unintentionally - other practices.

What we also have observed is that the editors do not discuss the challenges of internationalization, and implement only those means of internationalization that are explicitly stated in the journal evaluation regulations (the results of Set III). When they describe the internationalization of their journals and editorial practices, they do not consider, e.g. co-authorship with non-Polish scholars or other internationalization parameters that are discussed outside the Polish system, such as an international audience and an editorial board's geographic location. Most of the editors address their journals to national audience. Whereas, their journals are locally oriented. This means that the internationalization of journals stipulated by the science policy is understood as a means of fulfilling the requirements, i.e. reaching the expected values of the internationalization parameters rather than a means of changing the journal's orientation from a local to an international one. In other words, internationalization is mostly perceived as a way of gaming the point-based 
evaluation system not as stimulating the editorial policy transformation or the audience expansion.

\section{Conclusion}

The following conclusions relevant especially for policy makers can be drawn from the present study. A research evaluation system might motivate the internationalization of journals, but it should deemphasize the corrupted parameters. As our findings show, journals in the SSH are strongly connected to the surrounding society and language. Moreover, a majority of such journals are local and devoted only to the local audience. Our observation confirms the observation made by Giménez-Toledo et al. (2007) and Salager-Meyer (2015). Thus, the system of journal evaluation should acknowledge two types of journals in the SSH: those that are actually prestigious and internationally oriented or might become such, and those that are actually locally oriented and have implemented the highest standards of editorial practices. An updated and improved system of journal evaluation might encourage small journals (e.g. from a single university or region) to consolidate. Internationally-oriented journals should be motivated to increase their international audience, such as by publishing full texts in open access.

We would like to highlight that providing more detailed recommendations requires taking the prescriptive ground. It might be reasonable if the main goal of this ground is operationalization of a new science policy in the areas of journal evaluation. Actually, however, the science policy has not been updated.

Finally, a number of important limitations need to be considered. The limitations of the Set I and II make the generalization of results to other non-English-speaking countries difficult to achieve. If we assume that the journal editors' practices are closely connected with the research evaluation system in Poland, then we should expect that our findings are limited to the Polish case and using them to understand practices from different countries should be preceded by analyses of other science policy systems. Another political context could result in different conclusions from the same data, e.g. the presence of actual, not ostensible internationalization, or ostensible internationalization that reveals itself in different practices.

The limitations of the results of Set III (the small sample which serves for interpretation and understanding of the editorial practices) do not allow us to generalize about all Polish journals practices in the SSH. 
Nonetheless, this system sample is sufficient to ground the interpretation of the results of the quantitative study.

In conclusion, one important overall lesson is that it takes a concerted effort to prevent gaming of the editorial practices. The Polish case may be relevant also for various academic communities in other non-Englishspeaking countries especially from Central and Eastern Europe, despite the problem with the generalizability of results. It shows that academic communities need an explicit and open discussion on the ways in which internationalization parameters are used in journal evaluation procedures. Such a discussion should be one of the first steps for reducing and minimizing the unintended effects of internationalization parameters, and we hope that the results provided in the present study might be a good point of departure for this discussion.

\section{REFERENCES}

Aksnes, Dag W., Nicoline Frølich, and Stig Slipersæter. 2008. Science Policy and the Driving Forces behind the Internationalisation of Science: The Case of Norway. Science and Public Policy 35 (6): 445-457.

Albu, Cătălin Nicolae and Nadia Albu. 2015. Introduction to the Special Issue on Accounting Academia in Central and Eastern Europe. Accounting and Management Information Systems 14 (2): 247-274.

Bocanegra-Valle, Ana. 2013. The perceived value of English for academic publishing among ESP multilingual scholars in Europe. ESP Today 1 (1): $5-25$.

Brembs, Björn, Katherine Button, and Marcus Munafò. 2013. Deep Impact: Unintended Consequences of Journal Rank. Frontiers in Human Neuroscience 7: 291.

Buela-Casal, Gualberto, Pandelis Perakakis, Michael Taylor, and Purificación Checa. 2006. Measuring Internationality: Reflections and Perspectives on Academic Journals. Scientometrics 67 (1): 45-65.

Butler, Linda. 2003. Explaining Australia's increased share of ISI publications - the effects of a funding formula based on publication counts. Research Policy 32 (1): 143-155.

Campbell, Donald T. 1979. Assessing the Impact of Planned Social Change. Evaluation and Program Planning 2: 67-90.

Cohen, Jacob. 1988. Statistical Power Analysis for the Behavioral Sciences. 2nd ed. New York, NY: Lawrence Erlbaum Associates.

Creswell, John. 2014. Research Design: Qualitative, Quantitative, and Mixed Methods Approaches. Thousand Oaks, CA: Sage. 
Duszak, Anna and Jo Lewkowicz. 2008. Publishing Academic Texts in English: A Polish Perspective. Journal of English for Academic Purposes 7 (2): $108-120$.

Engels, Tim C. E., Truyken L. B. Ossenblok, and Eric H. J. Spruyt. 2012. Changing publication patterns in the Social Sciences and Humanities, 2000 2009. Scientometrics 93 (2): 373-390.

Frølich, Nicoline. 2006. Still Academic and National - Internationalisation in Norwegian Research and Higher Education. Higher Education 52 (3): 405-420.

Giménez-Toledo, Elea, Adelaida Román-Román, and Maria Dolores AlcainPartearroyo. 2007. From experimentation to coordination in the evaluation of Spanish scientific journals in the humanities and social sciences. Research Evaluation 16 (2): 137-148.

Gordin, Michael D. 2015. Scientific Babel: How Science Was Done Before and After Global English. Chicago, IL: The University of Chicago Press.

Gutiérrez, Javier and Pedro López-Nieva. 2001. Are International Journals of Human Geography Really International? Progress in Human Geography 25: 53-69.

Haustein, Stefanie. 2012. Multidimensional Journal Evaluation: Analyzing Scientific Periodicals beyond the Impact Factor. Berlin: De Gruyter Saur.

Hicks, Diana. 2012. Performance-Based University Research Funding Systems. Research Policy 41 (2): 251-261.

Hyland, Ken. 2016. Academic Publishing and the Myth of Linguistic Injustice. Journal of Second Language Writing 31: 58-69.

Jiménez-Contreras, Evaristo, Félix de Moya-Anegón, and Emilio Delgado López-Cózar. 2003. The evolution of research activity in Spain: The impact of the National Commission for the Evaluation of Research Activity (CNEAI). Research Policy 32: 123-142.

Keim, Wiebke. 2008. Distorted Universality: Internationalization and Its Implications for the Epistemological Foundations of the Discipline. Canadian Journal of Sociology 33 (3): 555-574.

Kozak, Marcin, Lutz Bornmann, and Loet Leydesdorff. 2014. How Have the Eastern European Countries of the Former Warsaw Pact Developed since 1990? A Bibliometric Study. Scientometrics 102 (2): 1101-1117.

Kulczycki, Emanuel. 2017. Assessing publications through a bibliometric indicator: The case of comprehensive evaluation of scientific units in Poland. Research Evaluation 26 (1): 41-52.

Kulczycki, Emanuel and Ewa A. Rozkosz. 2017. Does an expert-based evaluation allow us to go beyond the Impact Factor? Experiences from building a ranking of national journals in Poland. Scientometrics 111 (1), 417-442. 
Kulczycki, Emanuel, Marcin Korzeń, and Przemysław Korytkowski. 2017a. Toward an excellence-based research funding system: Evidence from Poland. Journal of Informetrics 11 (1): 282-298.

Kulczycki, Emanuel, Tim C. E. Engels, and Robert Nowotniak. 2017b. Publication patterns in the social sciences and humanities in Flanders and Poland. In: Proceedings of ISSI 2017 Wuhan: 16th International Society of Scientometrics and Informetrics Conference, Wuhan, China, 16-29 October 2017, pp. 95-104.

Kwiek, Marek. 2014. Structural Changes in the Polish Higher Education System (1990-2010): A Synthetic View. European Journal of Higher Education 4 (3): 266-280.

Kyvik, Svein. 1988. Internationality of the social sciences: the Norwegian case. International Social Sciences Journal 40 (1): 163-172.

Li, Li and Fenglian Zhang. 2003. Developing English-Language Academic Journals of China. Scientometrics 57 (1): 119-125.

Ministerstwo Nauki i Szkolnictwa Wyższego. 2008. Budujemy Na Wiedzy: Reforma Nauki Dla Rozwoju Polski.

Nederhof, Anton J., Rolf A. Zwaan, Renger E. De Bruin, and P. J. Dekker. 1989. Assessing the usefulness of bibliometric indicators for the humanities and behavioural sciences: A comparative study. Scientometrics 15 (5-6): 423-435.

Organisation for Economic Co-operation and Development. 2007. Revised field of science and technology (FOS) classification in the Frascati manual (Report No.: DSTI/EAS/STP/NESTI(2006)19/FINAL). Paris: Organisation for Economic Co-operation and Development.

Pajić, Dejan and Tanja Jevremov. 2014. Globally National - Locally International: Bibliometric Analysis of a SEE Psychology Journal. Psihologija 47 (2): 263-277.

Pontille, David and Didier Torny. 2010. The Controversial Policies of Journal Ratings: Evaluating Social Sciences and Humanities. Research Evaluation 19 (5): 347-360.

Reale, Emanuela, Annamaria Inzelt, Benedetto Lepori, and Peter Van Den Besselaar. 2012. The Social Construction of Indicators for Evaluation: Internationalization of Funding Agencies. Research Evaluation 21 (4): $245-256$.

Rey-Rocha, Jesús and María José Martín-Sempere. 2004. Patterns of the Foreign Contributions in Some Domestic vs. International Journals on Earth Sciences. Scientometrics 59 (1): 95-115.

Reza Davarpana, Mohammad and H. Behrouzfar. 2009. International Visibility of Iranian ISI Journals: A Citation Study. Aslib Proceedings 61 (4): 407-419. 
Salager-Meyer, Françoise. 2008. Scientific Publishing in Developing Countries: Challenges for the Future. Journal of English for Academic Purposes 7 (2): 121-132.

Salager-Meyer, Françoise. 2015. Peripheral scholarly journals: From locality to globality. Ibérica 30: 15-36.

Schneider, Jesper W., Kaare Aagaard, and Carter W. Bloch. 2014. What happens when funding is linked to (differentiated) publication counts? New insights from an evaluation of the Norwegian Publication Indicator. In Proceedings of the science and technology indicators conference 2014 Leiden 'Context Counts: Pathways to Master Big and Little Data', edited by E. Noyons, 543-550. Leiden: Universiteit Leiden.

Šipka, P. (2013). Bibliometric Quality of Serbian Journals 2002-2011: More Than Just a Dress for Success. Journal Publishing in Developing, Transition and Emerging Countries: Proceedings of the 5th|Belgrade International Open Access Conference 2012, 161-165. doi:10.5937/BIOAC-110

Sivertsen, Gunnar. 2016. Patterns of internationalization and criteria for research assessment in the social sciences and humanities. Scientometrics 107 (2): $357-368$.

Wolters, Gereon. 2013. European Humanities in Times of Globalized Parochialism. Bollettino della Società Filosofica Italiana 208: 3-18.

Wormell, Irene. 1998. Informetric Analysis of the International Impact of Scientific Journals: How 'international' are the International Journals? Journal of Documentation 54(5): 584-605.

Yue, Weiping and Concepción S. Wilson. 2004. An Integrated Approach for the Analysis of Factors Affecting Journal Citation Impact in Clinical Neurology. Proceedings of the American Society for Information Science and Technology 41 (1): 527-536.

Žic-Fuchs, Milena. 2014. The Future of Publications in the Humanities: Possible Impacts of Research Assessment. In New Publication Cultures in the Humanities edited by P. Dávidházi, 147-171. Amsterdam: Amsterdam University Press.

Zitt, Michel and Elise Bassecoulard. 1998. Internationalization of Scientific Journals: A Measurement Based on Publication and Citation Scope. Scientometrics 41 (1-2): 255-71.

\section{ACKnowledgments}

The authors would like to thank Krystian Szadkowski for his useful suggestions and remarks, and Zuza Wiorogórska for translating the abstract. Finally, we are also greatly indebted to the two anonymous reviewers for their helpful comments and inspiring criticisms. This work was sup- 
ported by the National Programme for the Development of Humanities in Poland [grant number 0057/NPHR3/H11/82/2014].

\section{ApPendix}

\section{Information about the journal}

The journal ID

The age of the journal

Group of science

Discipline

Number of points (Polish Journal Rankings from 2012, 2013, 2015)

\section{Information about the interview}

Interviewer

Location

Date

Length in $\min$.

\section{Main themes with sample questions from the interview}

Journal Audience

$\square \quad$ What is the nature of the journal: local or international? What is the most important characteristic of the journal?

$\square \quad$ Who constitutes the journal's audience?

$\square$ What kind of activities did the editorial staff implement to expand the scope of the audience? 
$\square$ Does the editorial board monitor who and how often reads and/ or cites the journal?

Science Policy-Driven Editorial Practices

$\square \quad$ What influences the editorial practices?

$\square$ What is the role of the Polish research evaluation system in the journal's publishing practices?

$\square \quad$ What is the role of the Polish Journal Rankings in the journal's publishing strategy? Have you been forced to change the journal's practices because of the regulations of the Polish Journal Rankings?

$\square \quad$ What kind of practices build the prestige of journals?

$\square \quad$ How should an ideal scholarly journal be published?

Dissemination practices

$\square$ How should the ideal of dissemination of the journal look like?

$\square$ How has the editorial staff tried to increase the visibility of the journal?

$\square \quad$ How do you disseminate the papers published in the journal?

$\square \quad$ Is the an open-access journal? If yes, why have you decided to adopt this model of dissemination?

$\square \quad$ Is the journal indexed in any bibliographic databases? If yes, please enumerate those databases and explain why you have chosen those the databases.

$\square \quad$ What have you changed in the editorial practices to be indexed in those databases?

$\square \quad$ What should an effective promotion of the journal look like?

Internationalization Practices

$\square \quad$ How have you internationalized the journal?

$\square \quad$ What are the benefits of the journal internationalization?

$\square$ What types of practices can attract international audience to a journal?

$\square$ How do you work with authors, reviewers, and editors from foreign countries?

In what language(s) does the journal publish the articles?

Journal Policies

$\square$ How have you changed the way of running the journal?

$\square$ Who has decided to implement the changes in the journal's policies? 
$\square$ How have you implemented the changes in the journal's policies?

Emanuel Kulczycki is the head of the Scholarly Communication Research Group and an Associate Professor at the Adam Mickiewicz University in Poznań, Poland. Since 2019, he is the chair of the European Network for Research Evaluation in the Social Sciences and the Humanities. His recent papers were published in 'Nature', 'Research Evaluation', 'Journal of Informetrics', and 'Scientometrics'.

Ewa A. Rozkosz is a post-doc at the Adam Mickiewicz University in Poznań, Poland. She is a co-author of a Polish translation of the Open Journal Systems. In her $\mathrm{PhD}$ thesis, she investigated the criteria and evaluation practices in social sciences and the humanities.

Aneta Drabek works in the Library of the University of Silesia in Poland. In her work, she focuses on constructing bibliographic databases and providing information to databases. Moreover, she instructs scholars how to use various data sources in their work. Aneta Drabek is a co-author of "Arianta," i.e. the largest and continuously updated database of the Polish journals. 